\title{
Jugular venous reflux and plasma endothelin-1 are associated with cough syncope: a case control pilot study
}

\author{
Chih-Ping Chung ${ }^{1,2}$, Chun-Yu Cheng ${ }^{1,2}$, Robert Zivadinov' ${ }^{3}$, Wei-Chih Chen ${ }^{4,5}$, Wen-Yung Sheng ${ }^{1}$, Yu-Chin Lee ${ }^{2,6}$, \\ Han-Hwa Hu ${ }^{1,2}$, Hung-Yi Hsu ${ }^{9,10,11+}$ and Kuang-Yao Yang ${ }^{6,7,8^{*}+}$
}

\begin{abstract}
Background: Jugular venous reflux (JVR) has been reported to cause cough syncope via retrograde-transmitted venous hypertension and consequently decreased cerebral blood flow (CBF). Unmatched frequencies of JVR and cough syncope led us to postulate that there should be additional factors combined with JVR to exaggerate CBF decrement during cough, leading to syncope. The present pilot study tested the hypothesis that JVR, in addition to an increased level of plasma endothelin-1 (ET-1), a potent vasoconstrictor, is involved in the pathophysiology of cough syncope.

Methods: Seventeen patients with cough syncope or pre-syncope (Mean[SD] $=74.63(12.37)$ years; 15 males) and 51 age/gender-matched controls received color-coded duplex ultrasonography for JVR determination and plasma ET-1 level measurements.

Results: Multivariate logistic analysis showed that the presence of both-side JVR (odds ratio [OR] $=10.77,95 \%$ confident interval $[\mathrm{Cl}]=2.40-48.35, p=0.0019)$ and plasma $\mathrm{ET}-1>3.43 \mathrm{pg} / \mathrm{ml}(\mathrm{OR}=14.57,95 \% \mathrm{Cl}=2.95-71.59$, $p=0.001$ ) were independently associated with the presence of cough syncope/ pre-syncope respectively. There was less incidence of cough syncope/ pre-syncope in subjects with the absence of both-side JVR and a plasma ET-1 $\leqq 3.43 \mathrm{pg} / \mathrm{ml}$. Presence of both side JVR and plasma ET-1 level of $>3.43 \mathrm{pg} / \mathrm{ml}$, increased risk for cough syncope/pre-syncope $(p<0.001)$.

Conclusions: JVR and higher plasma levels of ET-1 are associated with cough syncope/ pre-syncope. Although sample size of this study was small, we showed a synergistic effect between JVR and plasma ET-1 levels on the occurrence of cough syncope/pre-syncope. Future studies should confirm our pilot findings.
\end{abstract}

Keywords: Cough syncope, Endothelin-1, Jugular venous reflux

\section{Background}

Syncope is defined as a transient loss of consciousness with subsequent spontaneous recovery, resulting from global cerebral hypoperfusion [1]. Besides syncope, a lesser degree of compromised cerebral blood flow (CBF) may lead to pre-syncope symptoms, such as wooziness, light-headedness, nearly fainting sensation and/or visual dimming. Cough syncope refers to syncope upon

\footnotetext{
*Correspondence: kyyang@vghtpe.gov.tw

${ }^{\dagger}$ Equal contributors

${ }^{6}$ Department of Chest Medicine, Taipei Veterans General Hospital, Taipei 112, Taiwan

${ }^{7}$ Immunology Center, Taipei Veterans General Hospital, Taipei, Taiwan Full list of author information is available at the end of the article
}

coughing, [2] the pathogenesis of which is unclear and probably multifactorial.

Endothelin-1 (ET-1) is a potent vasoconstrictor peptide derived from vascular endothelial cells [3]. Besides its direct vasoconstriction effect, increased ET-1 levels may result in decreased nitric oxide (NO) availability, thereby predisposing to vasoconstriction $[4,5]$. ET-1 also contributes to the regulation of cerebral vascular tone. ET-1 levels have been shown as elevated in the plasma and cerebrospinal fluid (CSF) of subarachnoid hemorrhage (SAH) patients, with the presence of elevated ET-1 levels correlating with the persistence of cerebral vasospasm [4,6,7]. Additionally, ET-1 levels have been observed to

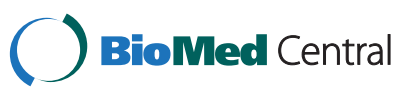


decline in the absence of cerebral vasospasm, [7] and the administration of ET- 1 antagonists prevents cerebral vasospasm [8]. Therefore, ET-1 is one of determinants of CBF. Endothelial dysfunction with imbalanced releases of $\mathrm{NO}$ and ET-1 has also been recognized in chronic obstructive pulmonary disease (COPD); those populations have been found with more frequent cough syncope $[9,10]$.

Jugular venous reflux (JVR) is found frequently in transient global amnesia, [11] transient monocular blindness patients, [12] and elderly people with more severe age-related white matter changes [12]. JVR may occur during a Valsalva maneuver (VM) or Valsalva-like activities, such as cough, when increased intrathoracic pressure is beyond the competence of internal jugular venous (IJV) valves. VM-induced JVR, which may retrogradely transmit venous hypertension into cerebral venous system, decreases cerebral perfusion pressure (CPP) and consequently reduces CBF during Valsalva-like activities [13-16]. It has been suggested that JVR plays a role in the pathophysiology of cough syncope [17]. However, the low incidence of cough syncope, disproportionate to the higher frequency of JVR, [18] implies that additional factors should be involved. In the present study, we hypothesized that (1) the presence of JVR is associated with cough syncope, and (2) there is an interactive effect between JVR and the plasma ET-1 levels on the occurrence of cough syncope.

\section{Methods}

\section{Subjects}

This was a prospective case-control pilot study. For valid statistical analyses, the numbers of recruited cough syncope/pre-syncope cases (case group) and age/gendermatched controls (control group) were set as 1:3. Between July/2009 and August/2010, Taiwanese patients consecutively enrolled at the Neurological and Chest Outpatient Clinics of Taipei Veterans General Hospital with cough syncope/pre-syncope were assessed for inclusion into this study. The definition of cough syncope and cough pre-syncope were defined as the presence of consciousness loss, and the presence of wooziness, lightheadedness, a nearly fainting sensation and/or visual dimming without consciousness loss, respectively, during involuntary coughing. Arterial blood pressure (ABP) measurement, eletrocardiography (EKG), eletroencephalography (EEG) and neck vascular duplex sonography were performed in all patients. Subjects eligible for participation in the current study had normal EKG and EEG studies, and the absence of neck arterial stenosis by duplex sonography. Exclusion criteria (including the control group) were a past history of stroke, ischemic heart disease, congestive heart disease, valvular heart disease, cardiac arrhythmia, or malignancy. Upon recruiting one eligible cough syncope/pre-syncope case, three age/ gender-matched controls were recruited from patients who visited the Chest Outpatient Clinic due to cough but no cough-related neurological symptoms. The study protocol was approved by the Institutional Review Board of Taipei Veterans General Hospital and was conducted in accordance with the Helsinki Declaration. Written informed consent was obtained from all participants or their authorized representatives before enrollment.

Vascular risk factors were defined according to international guidelines [19]. COPD was diagnosed per the definitions in the Global Initiative for Chronic Obstructive Lung Disease guidelines [20].

\section{JVR determination}

Neck color-coded duplex sonography was performed in all subjects with a 7-MHz linear transducer (Sonos 5500, Hewlett Packard, Andover, MA, USA) by the same technician, who was blinded to subjects' characteristics. The examination was done at least 2 hours after a light breakfast in the morning. On examination, subjects were in a head-straight, flat supine position after a quiet 10 minute rest. The IJV was initially insonated longitudinally and thoroughly from the proximal part of the neck base rostrally to the distal part at the submandibular level in order to detect any possible spontaneous JVR at baseline [11]. Then, the VM was performed by forcible expiration from subject's mouth into a flexible rubber tube connected to a manometer. Subjects were asked to reach $40 \mathrm{~mm} \mathrm{Hg}$ Valsalva pressure and maintain it for at least 10 seconds. During the VM, the distal margin of the window of the color signal was placed at the tip of the flow divider of the internal carotid artery. The color box was adjusted to include the entire lumen of the IJV; if retrograde color appeared in the center of the lumen, the retrograde flow would then be confirmed by Doppler spectrum. JVR was determined when the retrogradeflow color in the center of the lumen and the Dopplerflow waveform demonstrated reversal of flow for more than 0.5 seconds at baseline and/or during the VM (Figure 1) [11,15,21,22].

\section{Plasma ET-1 levels measurement}

Non-fasting venous blood samples were drawn before neck color-coded duplex sonography in all subjects, at a similar morning time to avoid a circadian variation and collected in the tubes containing EDTA. Plasma was separated from whole blood and stored at $-80^{\circ} \mathrm{C}$ until analysis. Plasma levels of ET-1 were measured using a commercially available immunoassay kit (R\&D Systems Inc., Minneapolis, MN, USA). The intra- and interassay coefficients of variation of ET-1 in our laboratory were $4.4 \%$ and $5.7 \%$. All measurements were performed in duplicate. 


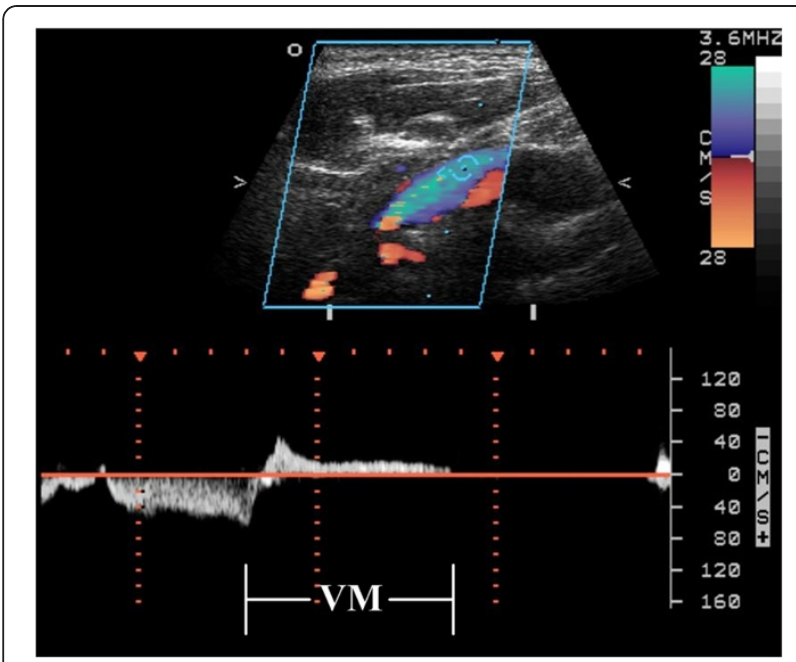

Figure 1 Retrograde flow detected by color duplex and in the Doppler spectrum during Valsalva maneuver (VM) is considered as jugular venous reflux (JVR).

\section{ABP changes during VM}

Since VM/cough-induced hypotension is presumed as one possible mechanism in cough syncope, [23,24] we also recorded $\mathrm{ABP}$ changes during the VM, a maneuver that mimics the effect of cough, by servocontrolled infrared finger plethysmography (Finapres, model 2300, Ohmeda Monitoring Systems, Englewood, CT, USA.) in patients with cough syncope and age/gender-matched controls. Experiments were performed in the morning at least 2 hours after a light breakfast. After at least 10 minutes of supine rest, two VMs were performed with a 5-minute interval between them. The second VM was used for data analysis. The VM was performed for a duration of 15 seconds, with intrathoracic pressure of 40 $\mathrm{mmHg}$ maintained and monitored by a pressure gauge connected to a flexible tube.

Beat-to-beat ABP measured for 15 seconds before the VM was averaged as baseline. Phasic changes in mean ABP with the VM were defined previously [15,25]. There are four distinct well described phases of ABP changes. With the beginning of the strain (phase I), there is a transient increase in $\mathrm{ABP}$ resulting from transmission of intrathoracic pressure to the arterial system. At phase II, continuously increased intrathoracic pressure will impede venous return to the heart and lead to a fall in ABP early in phase II (phase IIa). Then in late phase II (phase IIb), a sympathetic response to the fall in ABP will produce a rise in ABP. When the strain is relieved (phase III), more venous blood volume pools in the expanded intrathoracic veins due to sudden intrathoracic pressure decrement, which decreases left atrial filling and, subsequently, ABP. This is followed by an overshoot in ABP (phase IV), when atrial filling is normalized accompanied by remain-elevated sympathetic tone. Relative changes in mean $\mathrm{ABP}$ at each phase of the VM are calculated as the ratio of the magnitude of the phasic changes at each phase divided by the baseline measurements.

\section{Statistical analysis}

Continuous data are expressed as mean (SD). The nonparametric Mann-Whitney $U$ test was used to compare the case group and the control group. The $\mathrm{x}^{2}$ test was used for evaluating categorical variables, and Fisher's exact test was used for instances in which individual counts in any group were fewer than five. Univariate and multivariate logistic analyses were performed using odds ratio (OR) with a 95\% confidence interval (CI) to test the independent effect of factors associated with cough syncope/pre-syncope. To determine the predictive accuracy of ET-1 level for cough syncope, receiver operating characteristic (ROC) curve was constructed, and the area under the curve (AUC) was calculated. Based on the optimal cut-off value of plasma ET-1 level determined from the ROC curve, in univariate and multivariate analyses, we took $3.43 \mathrm{pg} / \mathrm{ml}$ as the cut-off point. Among JVRs of different severities and sides, we used the presence of both-side JVR to run the univariate and multivariate analyses. To test the interactive effects between JVR and the levels of plasma ET-1 on the presence of cough syncope/pre-syncope, we divided all subjects into four groups. Those groups were (1) the presence of both-side JVR with plasma ET-1 > $3.43 \mathrm{pg} / \mathrm{ml}$; (2) the absence of both-side JVR with plasma ET-1 > $3.43 \mathrm{pg} / \mathrm{ml}$; (3) the presence of both-side JVR with plasma ET-1 $\leqq 3.43 \mathrm{pg} / \mathrm{ml}$; and (4) the absence of bothside JVR with plasma ET- $1 \leqq 3.43 \mathrm{pg} / \mathrm{ml}$. Then we used Mantel-Haenszel $\mathrm{x}^{2}$ to test for trends across these four groups in the frequency of cough syncope/pre-syncope. For all tests, $p<0.05$ was considered statistically significant. All analyses were performed with SAS software, version 9.1 (SAS Institute Inc, Cary, NC).

\section{Results}

\section{Patient characteristics}

All cough syncope/pre-syncope cases presented with firsttime, cough-related neurological symptoms. We excluded one patient with severe internal carotid artery stenosis, and another patient with seizure history. In the end, there were 10 patients with cough syncope, 7 patients with cough pre-syncope, and 51 age/gender-matched control subjects recruited in the present study. In subjects with cough pre-syncope, upon cough all had a nearly fainting sensation (light-headedness, dizziness, etc.) and five (71.43\%) had visual dimming. All subjects in the case group developed a neurological symptom during a prolonged or repetitive vigorous cough. They did not experience syncope/pre-syncope at other times. Subjects with 
cough syncope/pre-syncope also had no vertigo, tinnitus, and evidence of convulsion or incontinence during cough. The demographic/clinical characteristics are demonstrated in Table 1 . The severity of COPD was similar between case and control groups. There were no significant differences in the demographic factors between case and control groups. In addition, there were no differences in the demographic characteristics, the frequencies of JVR, and plasma ET-1 levels between subjects with cough syncope and cough pre-syncope (Mann-Whitney $U$ and $\mathrm{x}^{2}$ test; data not shown).

JVR and plasma ET-1 level comparisons between cough syncope/pre-syncope and control groups

The case group had higher frequencies of right-side, leftside, and both-side JVR, respectively (Table 1), and also higher plasma ET-1 levels (Figure 2) compared with control group. All JVRs detected in the case group occurred during the VM. Five patients of the cough syncope group and six of the cough pre-syncope group complained of dizziness during the VM. In the normal group, all right-side JVRs were detected during the VM, whereas in the left-side JVR, two (11.11\%) were shown at baseline and 16 were detected during the VM.

The presence of JVR and higher plasma ET-1 levels predicted the presence of cough syncope/pre-syncope ROC curve plotted for studying the utility of plasma ET-1 level in predicting cough syncope are shown in Figure 3. The area under the ROC curve (AUC) for ET-1 was $0.8(p<0.001,95 \%$ confidence interval $0.68 \sim 0.92)$.
The optimal cut-off point of ET-1 for predicting cough syncope was $3.43 \mathrm{pg} / \mathrm{ml}$, with the sensitivity 0.59 and the specificity 0.90. Multivariate logistic analysis (Table 2) showed that the presence of both-side JVR and plasma ET-1 > $3.43 \mathrm{pg} / \mathrm{ml}$ were two independent factors associated with the presence of cough syncope/pre-syncope. Table 3 shows an interactive effect between both-side JVR and plasma levels of ET-1 on the occurrence of cough syncope/pre-syncope. There was a significant tendency that the presence of both-side JVR and plasma ET-1 > $3.43 \mathrm{pg} / \mathrm{ml}$ increased the frequency of cough syncope/ pre-syncope $(p<0.001)$. There was less incidence of cough syncope/pre-syncope in subjects with the absence of both-side JVR and a plasma ET-1 $\leqq 3.43 \mathrm{pg} / \mathrm{ml}$, however, a significant increased trend of cough syncope/ pre-syncope was seen in subjects with the presence of both-side JVR as well as a plasma ET-1 level $>3.43 \mathrm{pg} / \mathrm{ml}$.

\section{No difference of ABP changes during VM between} patients with cough syncope and normal controls

Ten patients with cough syncope [69.44(16.13) years; 9 males] and thirty age/gender-matched control subjects [69.44(16.13) years; 27 males] received the beat-to-beat ABP measurement at baseline and during the VM. The baseline and each phase of mean ABP between these two groups were similar [case group versus control group, $\mathrm{mmHg}$; baseline $=74.65(12.40)$ versus 77.91(14.33), $p=$ 0.525 ; phase $\mathrm{I}=90.40(14.91)$ versus $99.59(18.05), p=0.155$; phase $\mathrm{IIa}=65.07(16.95)$ versus $73.61(17.43), p=0.185$; phase $\mathrm{IIb}=78.77(19.17)$ versus $88.63(21.33), p=0.203$; phase $\mathrm{III}=54.27(19.39)$ versus $62.58(17.80), \quad p=0.218$;

Table 1 The characteristics and the frequencies of jugular venous reflux and plasma endothelin-1 levels in cough syncope/pre-syncope patients and control subjects

\begin{tabular}{|c|c|c|c|}
\hline & Cough syncope/pre-syncope $(n=17)$ & Controls $(n=51)$ & $p$ value \\
\hline Age, mean (SD), yr & $74.63(12.37)$ & $74.63(12.37)$ & \\
\hline Gender, M/F & $15 / 2$ & $45 / 6$ & \\
\hline \multicolumn{4}{|l|}{ Vascular risk factors, n (\%) } \\
\hline $\mathrm{HTN}$ & $4(23.53 \%)$ & $10(19.61 \%)$ & 0.729 \\
\hline Diabetes mellitus & $1(5.88 \%)$ & $5(9.80 \%)$ & 0.365 \\
\hline Hyperlipidemia & 0 & $4(7.84 \%)$ & 0.307 \\
\hline Smoking & $13(76.47 \%)$ & $41(80.39 \%)$ & 0.729 \\
\hline COPD & $14(82.35 \%)$ & $34(66.67 \%)$ & \multirow[t]{4}{*}{0.219} \\
\hline GOLD I & $6(43 \%)$ & $15(44 \%)$ & \\
\hline GOLD ॥ & $6(43 \%)$ & $12(35 \%)$ & \\
\hline GOLD III & $2(14 \%)$ & $7(21 \%)$ & \\
\hline Right-side JVR, n (\%) & $13(76.47 \%)$ & $25(49.02 \%)$ & 0.048 \\
\hline Left-side JVR, n (\%) & $11(64.71 \%)$ & $18(35.29 \%)$ & 0.034 \\
\hline Both-side JVR, n (\%) & $10(58.82 \%)$ & $8(15.69 \%)$ & 0.0005 \\
\hline Plasma ET-1 level, pg/ml & $3.64(1.23)$ & $2.39(1.01)$ & $<0.0001$ \\
\hline
\end{tabular}

Abbreviations: HTN = hypertension; COPD = chronic obstructive pulmonary disease; GOLD = Global Initiative for Chronic Obstructive Lung Disease guideline; JVR = jugular venous reflux; ET-1 = endothelin-1; SAH, subarachnoid hemorrhage. 


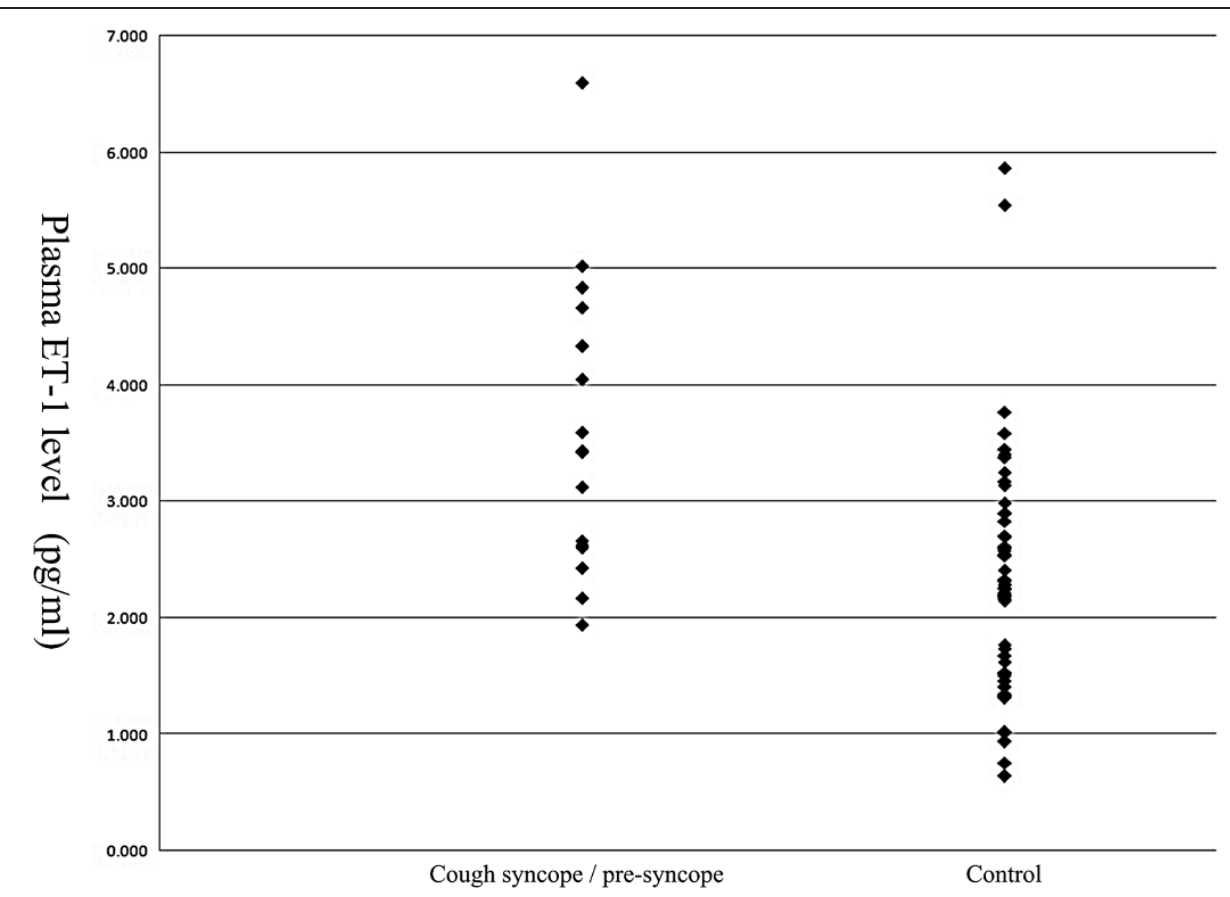

Figure 2 Plasma endothelin-1 levels in cough-syncope group $(n=17)$ and control group $(n=51)$.

phase IV=83.97(20.55) versus 91.47(15.45), $p=0.229]$. There was also no difference in each phasic change in mean ABP between case group and normal group [case group versus control group, \%; phase $\mathrm{I}=21.46$ (7.87) versus 28.80(17.73), $p=0.216$; phase $\mathrm{IIa}=-13.25$ (16.58) versus $-5.61(15.84), p=0.199$; phase $\mathrm{IIb}=5.56$ (23.52) versus $14.08(23.64), p=0.329$; phase $\mathrm{III}=-27.88$ (22.05) versus $-19.31(20.93), p=0.275$; phase $\mathrm{IV}=11.76$
(17.49) versus 19.41(23.17), $p=0.346]$. Three patients with cough syncope complained of dizziness during the VM.

\section{Discussion}

This pilot study is the first to prove that JVR is associated with cough syncope. Cough-induced JVR retrogradely transmits venous hypertension into the cerebral venous system, increases cerebral venous pressure or

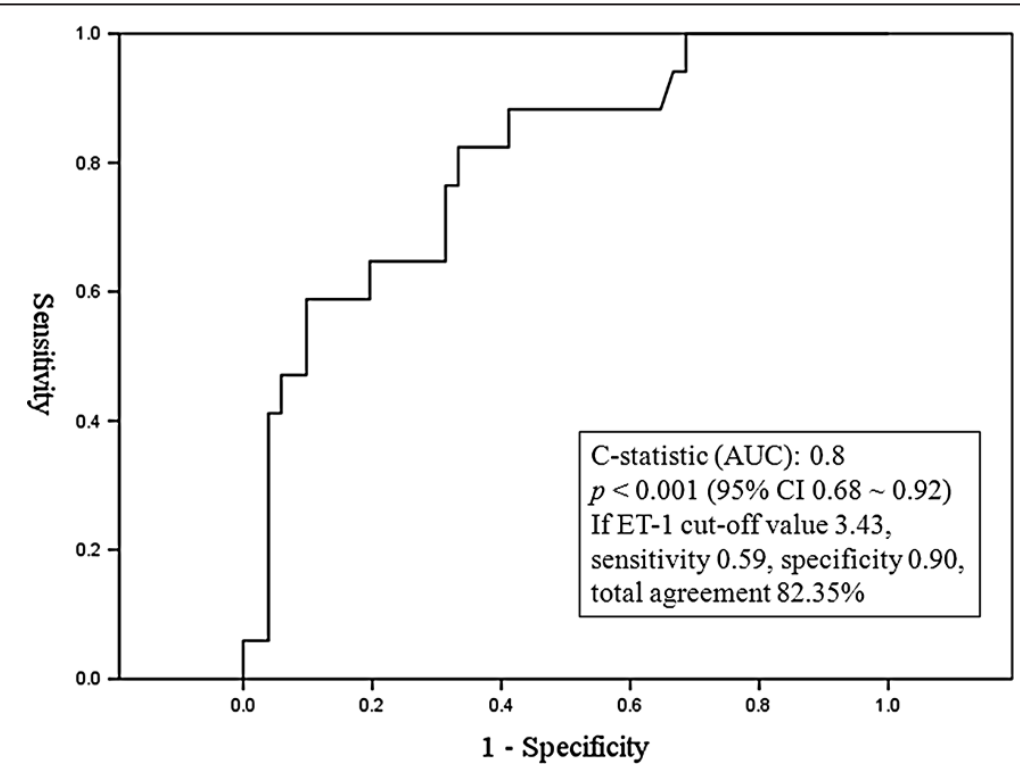

Figure 3 Receiver operator characteristic curve of the plasma endothelin-1 level in predicting cough syncope/pre-syncope patients. 
Table 2 Univariate and multivariate logistic analysis of factors associated with cough syncope/pre-syncope

\begin{tabular}{llll}
\hline & \multicolumn{1}{c}{ Univariate } & $\boldsymbol{p}$ value & Multivariate \\
\hline HTN & $1.26(0.34-4.71)$ & 0.729 & \\
\hline Diabetes mellitus & $0.56(0.06-5.30)$ & 0.365 & \\
\hline Hyperlipidemia & $0.73(0.63-0.85)$ & 0.307 & \\
\hline Smoking & $0.79(0.21-2.96)$ & 0.729 & \\
\hline Obesity & $0.62(0.12-3.21)$ & 0.518 & $10.77(2.40-48.35)$ \\
\hline COPD & $2.33(0.59-9.24)$ & 0.219 & $14.57(2.95-71.59)$ \\
\hline Both-side JVR & $7.68(2.25-26.16)$ & 0.001 & 0.0019 \\
\hline Plasma ET-1 $>3.43 \mathrm{pg} / \mathrm{ml}$ & $10.35(2.75-38.98)$ & 0.0006 & 0.0010 \\
\hline
\end{tabular}

Presented as OR $(95 \% \mathrm{Cl})$. Abbreviations: HTN = hypertension; COPD = chronic obstructive pulmonary disease; JVR = jugular venous reflux; ET-1 = endothelin-1.

intracranial pressure, decreases CPP, and might consequently reduce CBF during cough [13-17]. There are other known facts supporting the idea that increased cerebral venous or intracranial pressure might play a role in the pathophysiology of cough syncope [26,27]. One study measured IJV venous pressure during cough in patients with cough syncope and found equalized IJV venous pressure with $A B P$ [26]. In this situation, the net pressure gradient between $\mathrm{ABP}$ and venous pressure, the $\mathrm{CPP}$, would decrease and lead to reduced CBF. Another study using transcranial Doppler (TCD) showed a cessation of forward flow in the cerebral artery and diastolic flow reversal during cough-induced syncope [27]. This hemodynamic finding during cough suggests increased impedance in the downstream circulatory pathway, such as in conditions with elevated cerebral venous pressure.

Another novel finding is that higher plasma levels of ET-1 could predict the occurrence of cough syncope. The plasma ET-1 levels have been recognized as a biomarker for predicting vascular endothelial dysfunction [28]. Whether patients with cough syncope have impaired cerebral endothelial function that makes them susceptible to cerebral hypoperfusion is worthy of further study.

The prevalence of JVR shown in a large-population study is around $20-40 \%$ [18]. If JVR contributes to the pathophysiology, the question remains why only certain people with JVR have developed cough syncope. There might be different additional factors combining with JVR involved in the pathophysiology of different diseases which are found associated with JVR. Our previous study has demonstrated an interactive effect between JVR and aging on the severity of age-related white matter changes [22]. We suggested that JVR adding age-related cerebral vascular abnormalities precipitated cerebral hypoperfusion in elderly people. In the present study, we have also found that, besides JVR, elevated plasma ET-1 levels might play an additional role in the pathophysiology of cough syncope. This could explain the mismatch between the incidence of cough syncope and VM-induced JVR.

Previous studies showed a fall in systemic ABP during or at the end of coughing, or during the VM in patients with cough syncope, and presumed cough-induced hypotension might play a role in the mechanism $[23,24,29,30]$. In our study, however, there was no significant difference in mean ABP changes during and at the end of the VM between case and control groups. It is possible that, compared with a virtual cough, the VM had a relatively insufficient intrathoracic elevation and resulted in a non-significant ABP decrement during the $\mathrm{VM}$ in the case group. Because of discrepant findings between present and previously reported cough syncope results, $[23,24,29,30]$ we hypothesized that patients with cough syncope might have a higher central venous or intrathoracic pressure at baseline or/and during VM and VM-like activities (e.g. cough), and may induce vasovagal responses via baroreceptor stimulus during cough more easily than people without cough syncope. This could explain why people with cough syncope have both cough-induced hypotension and higher frequency of VM-induced JVR.

There are limitations in our pilot study. We enrolled relatively small sample size $(\mathrm{n}=17)$ and used post-hoc data analysis approach. While simulating the pathophysiology of cough syncope, we evaluated JVR in subjects with supine position instead of upright position, and used VM instead of a heavy cough. Additionally, CBF changes were not analyzed in the present study. Therefore, we could not demonstrate the relationship between JVR/plasma ET-1 levels and CBF changes in our subjects with cough syncope. However, our previous study using

\begin{tabular}{|c|c|c|c|c|}
\hline \multirow{2}{*}{$\begin{array}{l}\text { Both-side } \\
\text { JVR }\end{array}$} & \multirow{2}{*}{$\begin{array}{c}\text { Plasma ET-1, } \\
\mathrm{pg} / \mathrm{ml}\end{array}$} & \multicolumn{2}{|c|}{ Cough syncope/pre-syncope } & \multirow[t]{2}{*}{$p$ value } \\
\hline & & - & + & \\
\hline No & $\leqq 3.43$ & $38(92.7 \%)$ & $3(7.3 \%)$ & \multirow[t]{4}{*}{$<0.001$} \\
\hline Yes & $\leqq 3.43$ & $8(61.5 \%)$ & $5(38.5 \%)$ & \\
\hline No & $>3.43$ & $5(55.6 \%)$ & $4(44.4 \%)$ & \\
\hline Yes & $>3.43$ & 0 & 5 (100\%) & \\
\hline
\end{tabular}

Presented as numbers (\%). Abbreviations: JVR = jugular venous reflux; ET-1 = endothelin-1. 
transcranial Doppler did reveal an impact of JVR on CBF [15].

\section{Conclusions}

JVR and higher plasma levels of ET-1 are associated with cough syncope/pre-syncope. Although sample size of this study was small, we showed a synergistic effect between JVR and plasma ET-1 levels on the occurrence of cough syncope/pre-syncope. Future studies should confirm our pilot findings.

\begin{abstract}
Abbreviations
ABP: Arterial blood pressure; CBF: Cerebral blood flow; Cl: Confidence interval; CPP: Cerebral perfusion pressure; CSF: Cerebrospinal fluid; COPD: Chronic obstructive pulmonary disease; EEG: Eletroencephalography; EKG: Echocardiography; ET-1: Endothelin-1; GOLD: Global Initiative for Chronic Obstructive Lung Disease guideline; HTN: Hypertension; IJV: Internal jugular venous; JVR: Jugular venous reflux; NO: Nitric oxide; OR: Odds ratio; VM: Valsalva maneuver.
\end{abstract}

\section{Competing interests}

The authors declare that they have no competing interests.

\section{Authors' contributions}

All authors made intellectual contributions to the study and approved the final manuscript. CPC, HYH, and KYY designed the study and performed the experiments. CPC carried out the neck color-coded duplex ultrasonography. KYY carried out the ET-1 assays. CPC, CYC, RZ, WCC, WYS, YCL, HHH, HYH, and KYY participated in the analysis and interpretation of data. $\mathrm{CPC}, \mathrm{HHH}$, $\mathrm{HYH}$ and KYY drafted the manuscript and are guarantors of the paper.

\section{Authors' information}

Dr. Hu is editor-in-chief of Acta neurologica Taiwanica, Professor of Neurology, National Yang-Ming University, and Chief of section of Neurovascular Diseases, Neurological Institute, Taipei Veterans General Hospital. Dr. Yang is an advisory editor of Thoracic Medicine Taiwan and Associate professor of Pulmonary Medicine, Institute of Clinical Medicine, School of Medicine, National Yang-Ming University.

\section{Acknowledgements}

This work was supported, in part, by the research grants:NSC98-2314-B-075031-(CPC), NSC98-2628-B-075-003-MY3 (HHH), 100-2314-B-075-047-MY3 (KYY) from Taiwan National Science Council, and V99B2-004 (CPC), V99A-024, V99C1-167, V100C-159 (KYY) from Taipei Veterans General Hospital.

\section{Author details \\ ${ }^{1}$ Department of Neurology, Taipei Veterans General Hospital, Taipei, Taiwan. ${ }^{2}$ School of Medicine, National Yang Ming University, Taipei, Taiwan. ${ }^{3}$ Buffalo Neuroimaging Analysis Center, and the Department of Neurology, State University of New York at Buffalo, New York, USA. ${ }^{4}$ Department of Respiratory Therapy, Taipei Veterans General Hospital, Taipei, Taiwan. ${ }^{5}$ Division of Pulmonary Medicine, Department of Medical Affairs, Taipei Municipal Gan-Dau Hospital, Taipei, Taiwan. 'Department of Chest Medicine, Taipei Veterans General Hospital, Taipei 112, Taiwan. ${ }^{7}$ Immunology Center, Taipei Veterans General Hospital, Taipei, Taiwan. ${ }^{8}$ Institute of Clinical Medicine, Infection and Immunity Research Center, School of Medicine, National Yang Ming University, Taipei, Taiwan. ${ }^{9}$ Department of Neurology, Tungs' Taichung Metro Harbor Hospital, Wuci Township, Taichung County, Taiwan. ${ }^{10}$ School of Medicine, Chung Shan Medical University, Taichung, Taiwan. ${ }^{11}$ Department of Neurology, Taichung Veterans General Hospital, Taichung, Taiwan.}

Received: 18 December 2012 Accepted: 2 January 2013 Published: 16 January 2013

\section{References}

1. Kapoor WN: Evaluation and management of the patient with syncope. JAMA 1992, 268(18):2553-2560.
2. Moya A, Sutton R, Ammirati F, Blanc JJ, Brignole M, Dahm JB, Deharo JC, Gajek J, Gjesdal K, Krahn A, et al: Guidelines for the diagnosis and management of syncope (version 2009). Eur Hear J 2009, 30(21):2631-2671.

3. Yanagisawa $M$, Kurihara $H$, Kimura $S$, Tomobe $Y$, Kobayashi M, Mitsui $Y$, Yazaki Y, Goto K, Masaki T: A novel potent vasoconstrictor peptide produced by vascular endothelial cells. Nature 1988, 332(6163):411-415.

4. Pluta RM: Delayed cerebral vasospasm and nitric oxide: review, new hypothesis, and proposed treatment. Pharmacol Ther 2005, 105(1):23-56.

5. Thomas JE, Nemirovsky A, Zelman V, Giannotta SL: Rapid reversal of endothelin-1-induced cerebral vasoconstriction by intrathecal administration of nitric oxide donors. Neurosurgery 1997, 40(6):1245-1249.

6. Juvela S: Plasma endothelin concentrations after aneurysmal subarachnoid hemorrhage. J Neurosurg 2000, 92(3):390-400.

7. Seifert V, Loffler BM, Zimmermann M, Roux S, Stolke D: Endothelin concentrations in patients with aneurysmal subarachnoid hemorrhage. Correlation with cerebral vasospasm, delayed ischemic neurological deficits, and volume of hematoma. J Neurosurg 1995, 82(1):55-62.

8. Crowley RW, Medel R, Kassell NF, Dumont AS: New insights into the causes and therapy of cerebral vasospasm following subarachnoid hemorrhage. Drug Discov Today 2008, 13(5-6):254-260.

9. Bonekat HW, Miles RM, Staats BA: Smoking and cough syncope: follow-up in 45 cases. Int J Addict 1987, 22(5):413-419.

10. Peinado VI, Pizarro S, Barbera JA: Pulmonary vascular involvement in COPD. Chest 2008, 134(4):808-814.

11. Chung CP, Hsu HY, Chao AC, Sheng WY, Soong BW, Hu HH: Transient global amnesia: cerebral venous outflow impairment-insight from the abnormal flow patterns of the internal jugular vein. Ultrasound Med Biol 2007, 33(11):1727-1735.

12. Chung CP, Hsu HY, Chao AC, Cheng CY, Lin SJ, Hu HH: Jugular venous reflux affects ocular venous system in transient monocular blindness. Cerebrovasc Dis 2010, 29(2):122-129.

13. Dresser LP, McKinney WM: Anatomic and pathophysiologic studies of the human internal jugular valve. Am J Surg 1987, 154(2):220-224.

14. Fisher J, Vaghaiwalla F, Tsitlik J, Levin H, Brinker J, Weisfeldt M, Yin F: Determinants and clinical significance of jugular venous valve competence. Circulation 1982, 65(1):188-196.

15. Wu $H$, Sheng WY, Hu HH, Chung CP: Jugular venous reflux could influence cerebral blood flow: a transcranial Doppler study. Acta Neurol Taiwan 2011, 20(1):15-21.

16. Silva MA, Deen Kl, Fernando DJ, Sheriffdeen AH: The internal jugular vein valve may have a significant role in the prevention of venous reflux: evidence from live and cadaveric human subjects. Clin Physiol Funct Imaging 2002, 22(3):202-205.

17. Styczynski G, Dobosiewicz A, Abramczyk P, Styczynska M: Internal jugular vein valve insufficiency in cough syncope. Neurology 2008, 70(10):812-813.

18. Chung CP, Lin YJ, Chao AC, Lin SJ, Chen YY, Wang YJ, Hu HH: Jugular venous hemodynamic changes with aging. Ultrasound Med Biol 2010, 36(11):1776-1782.

19. Goldstein LB, Adams R, Alberts MJ, Appel LJ, Brass LM, Bushnell CD, Culebras A, Degraba TJ, Gorelick PB, Guyton JR, et al: Primary prevention of ischemic stroke: a guideline from the American Heart Association/ American Stroke Association Stroke Council: cosponsored by the Atherosclerotic Peripheral Vascular Disease Interdisciplinary Working Group; Cardiovascular Nursing Council; Clinical Cardiology Council; Nutrition, Physical Activity, and Metabolism Council; and the Quality of Care and Outcomes Research Interdisciplinary Working Group: the American Academy of Neurology affirms the value of this guideline. Stroke 2006, 37(6):1583-1633.

20. Rabe KF, Hurd S, Anzueto A, Barnes PJ, Buist SA, Calverley P, Fukuchi Y, Jenkins C, Rodriguez-Roisin R, van Weel C, et al: Global strategy for the diagnosis, management, and prevention of chronic obstructive pulmonary disease: GOLD executive summary. Am J Respir Crit Care Med 2007, 176(6):532-555.

21. Hsu HY, Chao AC, Chen YY, Yang FY, Chung CP, Sheng WY, Yen MY, Hu HH: Reflux of jugular and retrobulbar venous flow in transient monocular blindness. Ann Neurol 2008, 63(2):247-253.

22. Chung CP, Wang PN, Wu YH, Tsao YC, Sheng WY, Lin KN, Lin SJ, Hu HH: More severe white matter changes in the elderly with jugular venous reflux. Ann Neurol 2011, 69(3):553-559. 
23. Benditt DG, Samniah N, Pham S, Sakaguchi S, Lu F, Lurie KG, Ermis C: Effect of cough on heart rate and blood pressure in patients with "cough syncope". Heart Rhythm 2005, 2(8):807-813.

24. Chao AC, Lin RT, Liu CK, Wang PY, Hsu HY: Mechanisms of cough syncope as evaluated by valsalva maneuver. Kaohsiung J Med Sci 2007, 23(2):55-62.

25. Porth CJ, Bamrah VS, Tristani FE, Smith JJ: The Valsalva maneuver: mechanisms and clinical implications. Heart Lung 1984, 13(5):507-518.

26. Avramov K, Sztriha L, Makai A, Jambrik Z, Rudas L, Vecsei L: [Mechanism of cough syncope]. Orvosi hetilap 2004, 145(31):1625-1627.

27. Mattle HP, Nirkko AC, Baumgartner RW, Sturzenegger M: Transient cerebral circulatory arrest coincides with fainting in cough syncope. Neurology 1995, 45(3 Pt 1):498-501.

28. Cellini M, Strobbe E, Gizzi C, Balducci N, Toschi PG, Campos EC: Endothelin1 plasma levels and vascular endothelial dysfunction in primary open angle glaucoma. Life Sci 2012, 91(13-14):699-702.

29. Sharpey-Schafer EP: Effects of coughing on intrathoracic pressure, arterial pressure and peripheral blood flow. J Physiol 1953, 122(2):351-357.

30. Sharpey-Schafer EP: The mechanism of syncope after coughing. Br Med J 1953, 2(4841):860-863.

doi:10.1186/1471-2377-13-9

Cite this article as: Chung et al: Jugular venous reflux and plasma endothelin-1 are associated with cough syncope: a case control pilot study. BMC Neurology 2013 13:9.

\section{Submit your next manuscript to BioMed Central and take full advantage of:}

- Convenient online submission

- Thorough peer review

- No space constraints or color figure charges

- Immediate publication on acceptance

- Inclusion in PubMed, CAS, Scopus and Google Scholar

- Research which is freely available for redistribution 